http://dx.doi.org/10.18675/1981-8106.vol24.n47.p05-22

\title{
Trabalho ímprobo e fatigador
}

Daniel Cavalcanti de Albuquerque Lemos Universidade Federal de Juiz de Fora - MG, Brasil. daniel.cavalcanti@ufjf.edu.br

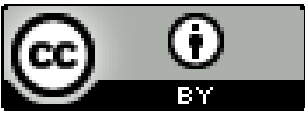

Educação: teoria e prática, Rio Claro, SP, Brasil - elSSN: 1981-8106

Está licenciada sob Licença Creative Common

\section{Resumo}

O presente artigo investiga as condições de trabalho, a situação econômica e a remuneração de professores e professoras do magistério público primário da Corte Imperial, durante a segunda metade do século XIX. Para tal análise é importante perceber em que condições era exercido o magistério nas escolas da Corte, considerando os problemas materiais, as condições das escolas, a questão dos salários, o poder de compra e a situação dos vencimentos dos professores em relação ao custo de vida, na cidade do Rio de Janeiro, à época, e em relação com os demais funcionários públicos da Corte Imperial. Para a questão salarial é importante, entre outros fatores, identificar a situação funcional dos professores, como a localização da escola, o número de alunos, o tempo de atuação no magistério. Utilizo para isso fontes produzidas pelos próprios professores, como cartas, artigos, abaixo-assinados e manifestos onde denunciam os problemas que encontram no exercício da profissão. Busco também entender o posicionamento do Estado Imperial sobre a situação dos professores, por intermédio de relatórios produzidos no âmbito da administração pública, recorrendo, ainda, às leis de ensino que fixam as vantagens e obrigações dos professores.

Palavras-chave: Salário. Trabalho. Profissão docente. Educação. Século XIX.

\section{Work unrighteous and fatigued}

\begin{abstract}
This article investigates working conditions, economic conditions and remuneration of teachers teaching the primary audience of the Imperial Court during the second half of the nineteenth century. For this analysis it is important understand what conditions was exercised work in schools of the Court, considering the material problems, the conditions of the schools, the issue of wages, purchasing power and status of teachers' salaries relative to cost of living at Rio de Janeiro and the period compared with the other officials of the Imperial Court. For the salary issue is important among other factors identify the functional status of teachers, as the school location, number of
\end{abstract}


students, the time of performance in teaching, I use it for sources produced by teachers, as letters, articles, below-signed and manifestos denounce problems they encountered in practice. This article works with positioning of the Imperial State on the status of teachers, through reports produced with the public administration, resorting to the laws that secure educational benefits and obligations of teachers.

Keywords: Work. Teaching profession. Education. Nineteenth Century.

\section{Trabajo ímprobo y fatigador}

\section{Resumen}

El presente artículo investiga las condiciones de trabajo, la situación económica y la remuneración de profesores y profesoras del magisterio público primario de la Corte Imperial, durante la segunda mitad del siglo XIX. Para tal análisis es importante tomar en cuenta en qué condiciones se ejercía el magisterio en las escuelas de la Corte, considerando los problemas materiales, las condiciones de las escuelas, la cuestión de los salarios, el poder de compra y la situación de los vencimientos de los profesores en relación al costo de vida, en la ciudad de Rio de Janeiro, en la época, y en relación con los demás funcionarios públicos de la Corte Imperial. Para la cuestión salarial es importante, entre otros factores, identificar la situación funcional de los profesores, como la localización de la escuela, el número de alumnos, el tiempo de actuación en el magisterio. Utilizo para eso fuentes producidas por los propios profesores, como cartas, artículos, peticiones y manifiestos donde denuncian los problemas que encuentran en el ejercicio de la profesión. Procuro también entender el posicionamiento del Estado Imperial sobre la situación de los profesores, por medio de informes producidos en el ámbito de la administración pública, recurriendo, aun, a las leyes de enseñanza que fijan los derechos y obligaciones de los profesores.

Palabras clave: Salario. Trabajo. Profesión docente. Educación. Siglo XIX.

\section{Introdução}

Trabalho Ímprobo e fatigador, assim era retratado, pelos próprios professores, o trabalho de um professor primário da Corte Imperial, na segunda metade do século XIX. Este artigo busca investigar as condições em que era exercido o magistério público primário nas escolas da Corte, os problemas materiais, as condições das escolas, a questão dos salários, o poder de compra e a situação dos vencimentos dos professores em relação a outros funcionários públicos da Corte Imperial. Utilizo para isso fontes produzidas pelos próprios professores, como cartas, artigos, abaixo-assinados e manifestos onde denunciam os problemas que encontravam no exercício da profissão. Para não ficar apenas com a posição dos professores, busquei, também, o 
posicionamento do Estado Imperial sobre o tema, utilizando relatórios produzidos no âmbito da administração pública. Recorro, ainda, às leis de ensino que fixavam as vantagens e obrigações dos professores. Outra fonte importante para perceber a situação dos professores pode ser encontrada nos romances do período, que trazem indícios de como e em que condições o magistério era exercido, por exemplo, em Memórias de um sargento de milícia, onde em um trecho é narrado o primeiro contato do personagem com a escola e com o professor, da impactante visão retratada pelo autor, emerge um cenário do que poderiam ser as escolas públicas primárias da Corte.

[...] morava este em uma casa da rua da Vala, pequena e escura. [...] recebido na sala, que era mobiliada por quatro ou cinco longos bancos de pinho sujos já pelo uso, uma mesa pequena que pertencia ao mestre, e outra maior onde escreviam os discípulos, toda cheia de pequenos buracos para os tinteiros; [...] Era este um homem todo em proporções infinitesimais, baixinho, magrinho, de carinha estreita e chupada, excessivamente calvo; usava de óculos, tinha pretensões de latinista, e dava bolos nos discípulos por dá cá aquela palha. Por isso era um dos mais acreditados da cidade. $\mathrm{O}$ barbeiro entrou acompanhado pelo afilhado, que ficou um pouco escabriado à vista do aspecto da escola, que nunca tinha imaginado (ALMEIDA, [1854] 1998, p. 27).

A descrição da escola no romance, pequena e escura, que deixou escabriado o futuro aluno, está próxima do que era a escola no século XIX. Em 1848, para o então Ministro dos Negócios do Império, Visconde de Macaé, a situação do ensino era de um "aspecto melancólico e triste". Segundo seu relatório do mesmo ano, um dos problemas a enfrentar era "a falta de edifícios de uma capacidade adequada às condições do ensino" ${ }^{1}$.

Os problemas dos edifícios escolares persistiram durante todo o século XIX, e podem ser observados nas falas dos agentes do Estado, nos relatórios dos Ministros do Império e nos relatórios dos inspetores da IGIPSC (Inspetoria Geral de Instrucção Primária e Secundária da Corte). Entre as soluções possíveis estavam a transferência das escolas e a instalação de novas escolas em prédios alugados apropriados segundo os padrões da época, ou a construção de prédios pelo Estado. Faria $F^{\circ}$ e Vidal (2005) apontam que, na década de 1870, tanto os profissionais que atuavam nas escolas como os que trabalhavam na administração da instrução destacavam o problema da precariedade dos espaços ocupados pelas escolas e defendiam com urgência a

\footnotetext{
${ }^{1}$ BN - Relatório do Ministro dos Negócios do Império, 1848.
} 
construção de espaços específicos para a instalação das escolas primárias, mobilizando, nesse sentido, argumentos financeiros, higiênicos e pedagógicos.

Além do problema pedagógico e de saúde, a falta de espaços próprios para as escolas era, ainda, segundo Faria $\mathrm{F}^{\circ}$ e Vidal (2005, p.52), um problema administrativo e financeiro. Administrativo, na medida em que as escolas, por estarem isoladas e distantes umas das outras, dificultavam a fiscalização; e financeiro, pois parte significativa das verbas da instrução era gasta com pagamento do aluguel da casa de escola e do professor. Para os professores os problemas referentes às escolas também podem ser entendidos como de ordem pedagógica e financeira.

Em um conjunto de cartas escritas pelos professores e destinadas às autoridades de ensino, que localizei no AGCRJ, (Arquivo Geral da Cidade do Rio de Janeiro), referentes à década de 1870, é possível perceber as críticas e intervenções dos professores sobre as escolas em que atuavam. As condições de algumas escolas, segundo os professores, eram críticas, como no ofício da professora Alcida Brandelina, que se recusava a morar e trabalhar no prédio designado para a instalação da Escola; segundo a professora, o prédio em questão apresentava até traços de desabamento, e trabalhar em tal espaço seria arriscar a vida de sua família e de seus alunos. ${ }^{2}$ Mas um dos problemas seria conseguir um prédio apropriado para instalar a escola.

Problema semelhante foi descrito pelo delegado da Freguesia da Lagoa, que, em carta à IGIPSC informa que a terceira escola de meninas da Freguesia estava prestes a ruir, e oferece a sala de sua casa para que a escola funcione, gratuitamente, até que se possa encontrar um novo local para instalá-la; informa, ainda, na carta, que a professora da referida escola é sua mulher.

Além da precária condição dos prédios, outro problema com o qual os professores se deparavam no exercício do ofício nas escolas era a falta de material apropriado, como mesa e bancos; muitas vezes, as escolas funcionavam sem o mobiliário suficiente e adequado, ou funcionavam com o mobiliário do próprio professor, como no caso dos professores da Freguesia da llha do Governador, que reclamavam à inspetoria que:

Há seis mezes Ex.mo sem que estas escolas funccionão sem a montação legal, que ambas necessitão de ser assoalhadas, forradas, envidraçadas e pintadas" (CÓDICE 11, 1 - 4, p. 256).

\footnotetext{
${ }^{2}$ Códice 11 - 2 - 30, 1868, p. 16-19.
} 
E, mesmo quando o prédio não ameaçava ruir e contava com mobiliário e material adequado, ele ainda podia ser considerado impróprio devido ao tamanho; professores e delegados reclamavam junto à inspetoria, sobre o tamanho dos prédios, como no caso da Freguesia de Santa Rita, em 1875, onde o delegado de instrução da Freguesia informou à inspetoria que a primeira escola pública feminina "funciona em local muito acanhado e que não comporta o número de alumnas 220 ". O delegado informou, ainda, que a professora não residia na escola, o que para o delegado não seria uma vantagem para o serviço público, e então propõe a mudança do colégio para um local mais apropriado, onde a professora pudesse morar. No ofício, o delegado informou a possibilidade de um outro prédio, e que:

[...] a professora já viu o imóvel e concordou em fazer a mudança, o aluguel actual custa 91:000 réis, o da nova escola custa 120:000 réis, mas como a professora vai morar nela e assim pagar 20:833 réis, o aumento seria de 7:501, diferença insignificante perto das vantagens (CÓDICE 11, 4-27).

O delegado utilizou argumentos financeiros e administrativos; financeiros, pois além do acréscimo do custo do novo aluguel ser pequeno, graças ao fato de a professora ter um desconto no ordenado por residir na escola, (desconto esse que reduzia de forma substancial o salário dos professores e que, por isso, foi alvo de diversas iniciativas pedindo sua extinção); e o argumento administrativo, já que com a professora residindo na escola ficaria mais fácil para o delegado a fiscalização da escola e da conduta da professora.

Gouvêa (2001), problematiza as relações entre o espaço público e o privado. Para ela, eles se confundem, pois a casa, muitas vezes, se constituiu em espaço das atividades remuneradas. As relações entre o público e o privado, como trabalhadas por Gouvêa, ajudam a pensar a questão da moradia do professor no espaço escolar. Ao dividirem o mesmo espaço, profissional e doméstico se confundem.

Sobre os descontos nos salários para o aluguel das escolas, em 1888, um grupo de professores elaborou um abaixo-assinado destinado à princesa Isabel; esses professores respondiam pela Comissão Executiva Permanente dos Professores Públicos Primários da Corte, e reclamavam sobre duas questões: o salário insuficiente e o desconto dos salários para aluguel das residências. Ao longo das décadas de 1870 e 
1880, os professores, em diversos momentos, pediram o fim dos descontos, como também a construção de prédios apropriados para as escolas. A construção desses espaços apropriados, na década de 1870, começou sob iniciativa da Câmara Municipal da Corte, com um edifício apropriado para os trabalhos do ensino primário e, segundo o ministro Paulino Soares de Sousa, em seu relatório, esse seria o "primeiro na Corte". Nesse caso, o ministro se refere à escola construída na Freguesia da Glória.

A questão salarial era a queixa mais recorrente dos professores no período, Oliveira ([1873] 2003), para analisar a situação dos vencimentos dos professores, comparou a situação do magistério em diferentes países, com base nos relatórios de M. Hippeau ${ }^{3}$, e concluiu que em toda a parte os professores eram mal remunerados, não se excetuando nem mesmos os países por eles considerados "clássicos da instrução", como a Prússia e os Estados Unidos. Assim, "o fato é geral e não deixa de ser uma vergonha para os estados e prejuízos para os povos", o que pode "servir de desculpa para o Brasil, país novo e sem recursos" (OLIVEIRA, [1873] 2003, p. 224). A imagem do professor na miséria era utilizada pelos professores brasileiros da Corte Imperial. Em 1871, no Manifesto dos Professores Públicos Primários da Corte, os professores informaram que:

[...] temos soffrido resignados toda a sorte de injustiças. Agora porem, que a taça transbordou com a repulsa que acabamos de soffrer quando pedimos aos poderes do Estado que nos tirassem da miséria, tomamos a resolução de vir perante vós, que constitui o poder real da nação, articular nossas queixas e pedir justiça (MANIFESTO DOS PROFESSORES PÚBLICOS PRIMÁRIOS DA CORTE IMPERIAL, 1871, p. 4).

Assim, os signatários do Manifesto expressaram não só a condição de miséria a que estavam submetidos, como a forma que se sentiam diante do Estado e, desse modo, justificando o fato de estarem se dirigindo ao povo pela falta de acolhida das autoridades competentes às solicitações que a elas foram endereçadas, pois, ainda segundo o manifesto:

As mais lisongeiras promessas Ihes forão feitas. Até conselhos receberão do próprio ministro para que moderassem o pedido que fazião. Aceitarão a correção e pedirão o que indicára o ministro sob a promessa de sua palavra de que declararia aceitável a emenda ao orçamento. Não sabemos se o fez. É natural que o fizesse; mas o certo é que nada obtiverão (MANIFESTO DOS PROFESSORES PÚBLICOS PRIMÁRIOS DA CORTE IMPERIAL, 1871, p. 7).

\footnotetext{
${ }^{3}$ Sobre o relatório de Hippeau, cf. Gondra (2001).
} 
A situação dos professores no tocante aos salários, como já visto, foi reconhecida por Almeida de Oliveira ([1873] 2003) em sua obra, pelos professores em suas queixas no Manifesto, nos abaixo-assinados e pela imprensa. Alambary Luz, editor do jornal pedagógico $A$ Instrucção Publica, identificava a carreira do magistério, fundamentalmente, como uma carreira de pobres. Os homens e as mulheres que se dedicavam ao ensino primário no Império seriam, segundo ele, oriundos das camadas pobres da sociedade. O professor Carlos Brazil, que em 1872 regia a escola pública de meninos da Freguesia do Espírito Santo, também já havia publicado artigos sobre a situação de professores, dirigindo suas queixas ao Ministério do Império e à Inspetoria de Instrução Pública da Corte. Para ele, os professores públicos eram pessoas pobres e que recebiam baixos salários. ${ }^{4} \mathrm{O}$ próprio Ministério do Império, ao longo dos anos e com diferentes ministros à frente, reconheceu o problema do "profundo descontentamento em que vive o professorado, resultante da falta de recompensa pecuniária suficiente" (RELATÓRIO DO MINISTRO DOS NEGÓCIOS DO IMPÉRIO, 1848, p. 36).

O Manifesto dos Professores Públicos Primários da Corte é, em parte, uma reação ao relatório do Ministério dos Negócios do Império, apresentado em 1870, onde, na parte dedicada à instrução, informava: "Sinto pois ter de dizer-vos que as condições da instrucção primária nessa Corte estão ainda longe de satisfazer as necessidades sociaes", e atribui isso ao fato que as escolas ficavam aquém do que poderiam apresentar por "falta de bons professores" (BRASIL, 1868 p. 23-24).

Mas assim como as acusações à qualidade dos professores estão presentes, os professores também registraram que:

[...] não há ministro novo que não diga no seu primeiro relatório que somos ignorantes, e que depois não modifique o seu juízo reconhecendo a injustiça que nos fez! (MANIFESTO DOS PROFESSORES PÚBLICOS PRIMÁRIOS DA CORTE IMPERIAL, 1871 p. 19).

Já os professores, insistiam na questão salarial. Tão baixos que, no Manifesto de 1871, reclamavam que o valor do salário era insuficiente para pagar as necessidades básicas, relegando-os à miséria:

Sim, Ex., senhor, é preciso que se diga, toda a verdade a V. Ex.: os professores públicos da Corte vivem na miséria. Indagam ainda ao conselheiro se não seria indecoroso ao Estado que: [...] os professores,

\footnotetext{
${ }^{4}$ A Instrução Pública, 30/06/1872.
} 
continuem estes a ter de ordenado $66 \$ 666$, e sejão forçados a deixar suas mulheres e filhas entregues talvez a prostituição, se lhes não valer o pão da caridade?! (MANIFESTO DOS PROFESSORES PÚBLICOS PRIMÁRIOS DA CORTE IMPERIAL, 1871, p. 18).

À questão salarial, os professores agregavam, também, a defesa das competências profissionais dos professores. No mesmo Manifesto, questionaram como:

[...] uma classe inteira de funcionários publicos, os professores da Corte que, segundo o manifesto, são a "classe talves a mais importante dos servidores do Estado", mas [...] vive oprimida, ludibriada, escarnecida, e, o que mais é, humilhada pela injustiça com que os poderes do estado a apellidão constantemente de ignorante! (MANIFESTO DOS PROFESSORES PÚBLICOS PRIMÁRIOS DA CORTE IMPERIAL, 1871, p. 2).

Mas, como exerciam o magistério os professores que enfrentavam as condições até aqui descritas? Que homens atuavam no magistério público primário das escolas da Corte? Manoel José Pereira Frazão, protegido pelo pseudônimo de Professor da Roça, respondeu a essas questões em uma série de artigos relativos à instrução pública da Corte, publicados no jornal O Constitucional, em março e abril de 1863. A resposta era a seguinte:

\footnotetext{
Dos homens distinctos que conta hoje a classe (que os conta) uns são distrahidos com occupações de diversa ordem, e só dão ao magisterio a hora designada para leccionar, e isso mesmo nem sempre; outros fazem do magisterio uma ante-camara para esperarem os melhoramentos que almejam.

Commo leccionam os primeiros? Cançados de mil outros afazeres, qual atarefado da politica, qual dos trabalhos de sua repartição, que Ihe absorveria todo o tempo, não é possivel que satisfaçam ás condições de um professor dedicado. De minimis non curat proetor. Vejamos os segundos. Estes, tendo sempre em mira melhorar de posição, estão attentos ao lado donde lhes acenam maiores vantagens.

Ora, esse estado anormal do espirito de uns e outros é incompativel com a assiduidade indispensavel ás lidas do magisterio! (O CONSTITUCIONAL, 21 de Março de 1863).
}

Professores atarefados com os afazeres da escola, muitas vezes ocupados ainda com comissões de exames ou com a participação obrigatória nas Conferências Pedagógicas, para complementar os baixos salários, se ocupam exercendo negócios estranhos ao magistério. Como foi o caso do professor Jorge Roberto da Costa que, em 1879, lecionava na Freguesia de Jacarepaguá. O professor foi denunciado por moradores da região por ter um negócio de taberna a pouca distância da escola que regia, muitas vezes descuidando dos deveres de professor; junto a essa denúncia encaminhada ao delegado de instrução, os moradores também questionaram a 
moralidade do professor: "É com pesar que dizemos, mas é forçoso declarar, que um professor habituado à embriaguez não pode ser modelo aos discípulos" (CÓDICE 11, 4 15, p. 233).

Diante dos baixos salários, o magistério primário era visto por alguns, conforme descrito pelo "professor da roça", como uma ocupação transitória à espera de uma ocupação mais rentável, muitas vezes dentro do serviço público.

Podemos perceber pelas fontes, tanto aquelas produzidas pelo Estado Imperial como as produzidas pelos professores, e mesmo na análise de Oliveira ([1873] 2003), que os salários dos professores eram baixos para os padrões da época. Mas tentar determinar o significado do valor dos salários dos professores públicos primários significa trabalhar um conjunto de variáveis que devem ser tomadas em consideração, como, por exemplo, o poder de compra desse salário no período estudado, a situação funcional do professor (se era titular da cadeira ou adjunto no primeiro, segundo ou terceiro ano), a localização da escola, o número de alunos, o tempo de serviço, dentre outras. Sara Jane Alves Durães (2007) realizou um importante trabalho sobre a remuneração do trabalho docente na segunda metade do século XIX, na província de Minas Gerais. Acerca do valor de ser professor naquele período, Durães (2007) afirma que a remuneração deve ser analisada como decorrente de valores historicamente construídos e nas relações vividas no interior da escola e da esfera pública. E aponta, como pontos dificultadores para trabalhar sobre o salário dos professores daquela época

[...] o número excessivo de leis, dados dispersos, diferentes remunerações variando de acordo com sexo do professor, situação funcional [...] uma outra dificuldade de ordem teórica, corresponde ao fato de as análises da remuneração do trabalho docente serem muito polêmicas, e até mesmo contraditórias (DURÃES, 2007, p. 147).

Com esse alerta, tento descrever um quadro sobre a remuneração dos professores públicos primários da Corte. Pelo decreto n. $1331 \mathrm{~A}$, de 17 de fevereiro de 1854, que regulamenta a reforma do ensino primário e secundário da Corte, os professores seriam remunerados de acordo com o Título II, Capítulo I do regulamento, que trata das "Condições para o magisterio publico; nomeação, demissão e vantagens para os professores" (1854, p. 50), que, no artigo 25 determinava os seguintes valores: “Os professores das escolas de segundo grao, $1.000 \$ 000$ de ordenado e $400 \$ 000$ de 
gratificação Os das escolas de primeiro grao, $800 \$ 000$ de ordenado e $200 \$ 000$ de gratificação" (DECRETO n. 1331 A, de 17 de fevereiro de 1854, p. 52).

Ainda segundo o regulamento de 1854, o artigo 30 incumbia ao Inspetor Geral uma série de obrigações, entre elas:

\section{$\S$ 12. Propor ao Governo}

1‥ Gratificações extraordinárias, e augmento de vencimentos para os professores públicos, nos casos e pelo modo marcados nos Art. 28 e 31 . (1854, p. 46).

Essas gratificações seriam correspondentes ao aproveitamento e ao tempo de exercício no magistério público. Mas como considerar os valores dos salários pagos, em 1854, para os professores primários? Um primeiro esforço foi situar o salário dos professores primários da Corte com professores de outras províncias do império, tentando perceber se existia uma disparidade entre valores. Segundo o Relatório do Presidente da Província de Minas Gerais, no ano de 1859, as professoras da capital recebiam $800 \$ 000$ enquanto os professores de Mariana e da capital entre $700 \$ 000$ e $800 \$ 000$ (DECRETO n. $1331 \mathrm{~A}$, de 17 de fevereiro de 1854, p. 54).

Diferente do caso da Corte, que não fazia diferença entre os valores pagos aos professores e professoras, tanto na Província de Minas Gerais como na Província de Santa Catarina, eram estipulados valores diferentes para cada sexo. Estudando a qualificação do trabalho docente em Minas Gerais, no século XIX, Durães (2009, p.175) constata que:

Em linhas gerais, a remuneração do trabalho docente era determinada em função do sexo do professor; da situação funcional - se efetivo, substituto, vitalício ou interino -; da localização da escola - rural, urbana, distrito, freguesia e vila-; do número de alunos(as); do tempo de atuação e outros.

Essa remuneração, de acordo com as variáveis apresentadas por Durães (2009), pode ser também observada nas informações contidas na coleção de leis da província de Santa Catarina.

Tabela 1 - Província de Santa Catarina, 1854 - Ordenado anual dos Professores das Escolas de Primeiras Letras

Ano Capital Cidades e vilas Freguesias

\begin{tabular}{lccc}
\hline $\begin{array}{l}\text { Professores } \\
350 \$ 000\end{array}$ & 1854 & $600 \$ 000$ & $400 \$ 000$ \\
$\begin{array}{l}\text { Professoras } \\
300 \$ 000\end{array}$ & 1854 & $450 \$ 000$ & $350 \$ 000$ \\
\hline
\end{tabular}


Fonte: Coleção de leis provinciais, 1835-1860

Na Província de Santa Catarina, em 1854, mesmo ano do regulamento da Corte, encontramos para os professores da capital o valor de $600 \$ 000$ e para as professoras 450\$000. Respectivamente $200 \$ 000$ e $350 \$ 000$ a menos que os professores e professoras da Corte no mesmo ano, contando apenas os salários e não levando em consideração a gratificação de $200 \$ 000$ dos professores da Corte. Segundo o Manifesto dos Professores Públicos Primários da Corte Imperial:

Comparando-se os vencimentos dos professores públicos em todas as províncias do Império, [...], se verifica que os que residem na corte, onde as necessidades da vida são mais exigentes, são os mais mal retribuídos (MANIFESTO DOS PROFESSORES PÚBLICOS PRIMÁRIOS DA CORTE IMPERIAL, 1871, p. 16-17).

Considerando-se que cada lugar tinha condições de consumo e custo de vida diferentes, ter os salários iguais poderia representar padrões de vida diferentes, dependendo de onde se vivia. Em geral, as gratificações não eram consideradas partes integrantes do salário, como demonstram os professores da Corte no Manifesto dos Professores Públicos Primários da Corte, enviado, em 1870, para o então ministro Paulino Soares de Souza que tratava de aumento de salários. Nesse Manifesto:

Os professores públicos de instrucção primaria da corte, depois de haverem solicitado o beneplácito de V. Ex., requererão ao corpo legislativo augmento de seus ordenados; e esperavão deferimento de sua petição, confiados, quer na justiça de sua causa, quer no interesse que lhes pareceu tomarem por sua desditosa sorte alguns membros conspícuos daquella augusta câmara, quer finalmente, no apoio que foi garantido pela honrada palavra de V. Ex. (MANIFESTO DOS PROFESSORES PÚBLICOS PRIMÁRIOS DA CORTE IMPERIAL, 1871, p. 18).

Mas o apoio não aconteceu, ou pelo menos não como desejavam os professores, já que ao invés do aumento eles receberiam uma gratificação, o que segundo o Manifesto:

Com effeito, Ex. senhor, um argumento de vencimentos na razão de serviços prestados e por prestar, importa nada mais nada menos, que uma gratificação de mais (pro labore) aos que a merecem. Nada mais justo. Será, pois, um incentivo para desafiar a actividade dos professores no desempenho de seus deveres, nunca, porém, um melhoramento para a classe! Este só poderá dar-se com o augmento dos ordenados, por serem estes os únicos vencimentos que percebe o empregado publico, quando prostado no leito da dor (MANIFESTO DOS PROFESSORES PÚBLICOS PRIMÁRIOS DA CORTE IMPERIAL, 1871, p. 18). 
Além dos valores das gratificações, é importante considerar, como já foi dito, o custo de vida diferenciado de cada local, o que é considerado inclusive pelas Províncias de Minas Gerais e Santa Catarina, que estipulavam valores diferenciados para os professores e professoras da capital e das maiores cidades. Como informaram, ainda, os professores no Manifesto destinado ao ministro do império:

E V. Ex., que conhece o estado actual das cousas nesta cidade, comprehende que o professor que só dispõe de $66 \$ 666$ para com elles pagar casa, e a quem Ihe sirva, e ainda sustentar mulher e filhos, pagar medico e botica, etc., diga-se a verdade vive na miséria! (MANIFESTO DOS PROFESSORES PÚBLICOS PRIMÁRIOS DA CORTE IMPERIAL, 1871,p. 19).

Tentando perceber o "estado das cousas nesta cidade", busquei indícios sobre o custo de vida para a Corte no período do Manifesto; fui atrás de preços de alguns serviços na Corte Imperial, utilizando como fonte os produtos anunciados no Almanak Laemmert de 1870 e 1871, e em informações a esse respeito em escritos dos professores. A queixa dos professores, no trecho do Manifesto acima citado, refere-se ao salário mensal de $66 \$ 666$, que era insuficiente para o sustento da família e os pagamentos como os de uma casa. Sobre o preço dos aluguéis no período, consegui informações graças ao ofício do delegado da Freguesia de Santa Rita, informando sobre a mudança de uma escola; segundo esse delegado, o aluguel do prédio onde se encontrava a escola custava $91 \$ 000$, e que o da nova escola custaria ao Estado $120 \$ 000$, valores incompatíveis com o salário de $66 \$ \$ 666$, o que já bastaria para demonstrar a validade da crítica contida no Manifesto. Mas, supondo que esses valores representassem a média dos aluguéis daquela época, como os professores conseguiriam pagar um lugar para morar? Vale lembrar que o mais comum naquele período era o professor residir na própria escola. O ofício do delegado de Santa Rita ajuda a responder a questão, pois informava que "a professora vai morar nela e assim pagar 20\$833" (CÓDICE 11, 4-27). Morando na Escola, e pagando parte do aluguel com o governo, sobravam à professora $45 \$ 833$ mensais para os demais gastos. Na hipótese de um professor, com os mesmos valores de salário e aluguel, e que tirasse seu sustento apenas do magistério, já que pelo regulamento de 1854, no artigo 33, "FicaIhe absolutamente prohibida qualquer profissão comercial ou industrial". 
Levando em conta que do salário de 66\$666 mensais, depois de pagar o aluguel do prédio que lhe servia de residência e de local de trabalho no valor de $20 \$ 833$, o professor tinha, ainda, $45 \$ 833$, totalizando, mensalmente, apenas esses gastos.

Outro aspecto que pode ajudar a entender o valor do salário dos professores públicos primários da Corte é colocá-lo em comparação com outros profissionais do serviço público. Na Corte Imperial, no ano de 1871, em diferentes momentos os professores, que se consideravam "uma das classes mais importantes do funcionalismo público" se sentiram menosprezados por parte do Governo, argumentando que os contínuos e os correios de secretarias, a quem não se exigia formação nem responsabilidades, recebiam mais que os professores públicos primários. Ao reivindicar melhores salários ao poder legislativo, os professores lembravam-se da importância do serviço prestado:

E com effeito, Exm. Senhor, não precisa de grande esforço de intelligencia; o simples bom-senso basta para fazer comprehender que a aquillo que chamamos meninos é nada menos que a própria NAÇÃO, que hoje passa pelas nossas mãos; e que a missão de preparar a nação futura não pode já continuar a ser menoscabada, a ponto de se dar a um professor publicona corte um ordenado de 800\$, quando os contínuos e correios das secretarias tem 1:00\$000! (MANIFESTO DOS PROFESSORES PÚBLICOS PRIMÁRIOS DA CORTE IMPERIAL, 1871, p. 15).

Durães (2007), estudando a questão dos salários dos professores em relação com outros funcionários públicos na província de Minas Gerais, percebeu que, apesar de uma maior exigência aos professores, os seus salários eram mais baixos que de outros funcionários públicos:

Segundo o regulamento $\mathrm{n} .44$, de 1859 , havia tendência de a remuneração
do professor do sexo masculino das escolas primárias de 1 e e 20 graus
aproximar-se da remuneração do amanuense. Era função do amanuense
executar qualquer escrituração de trabalho que fosse exigida pelo agente
geral ou revisor. No momento do concurso, exigia-se do candidato "a
melhor letra, mais correta ortografia e maior perícia na prática das 4
operações fundamentais de aritmética (Minas Gerais, regulamento n. 44 ,
1859 , art. 267, p. 94 ). Como visto, para o exercício do cargo de amanuense
não era exigida nenhuma formação específica. Nesse sentido, eram exigidos
conhecimentos mais elementares do que os exigidos para o exercício do
trabalho docente (DURÃES, 2007, p. 156).

Enquanto dos professores era exigido postura moral e intelectual compatível com o cargo, diploma de capacidade, aprovação em concurso, onde deveria aprestar atestados de moralidade. Deveria ter formação específica (como adjuntos ou em escolas normais), e uma vez aprovado deveria lidar com a responsabilidade atribuída 
ao cargo de professor devido à relevância social do trabalho realizado. Já do amanuense, no momento do concurso, exigia-se "a melhor letra, mais correta ortografia e maior perícia na prática das 4 operações fundamentais de aritmética" (DURÃES, 2007)

No caso da Corte Imperial, os próprios professores primários perceberam a desvalorização do magistério em relação a outras funções públicas, no Manifesto, os professores realizaram essa comparação e a apresentaram ao imperador Pedro II:

Senhor - Parece impossível que Vossa Magestade não fique sorprendido, como toda nação o ha de ficar, quando souber que nesta corte, um correio, um continuo de secretaria tem 1:400\$000, quando nenhuma habilitação se exige, nem responsabilidade; e que um professor tem 1:200\$000, sendo o ordenado de $800 \$ 000$ ! (MANIFESTO DOS PROFESSORES PÚBLICOS PRIMÁRIOS DA CORTE IMPERIAL, 1871, p.12).

O ordenado, conforme descrito no Manifesto de 1871, permanece igual ao previsto no regulamento de 1854, contabilizando a gratificação prevista também em 1854 de 200\$000. Podemos perceber que, em 17 anos, o salário do professor teve apenas mais uma gratificação no valor de $200 \$ 000$. Diante disso, os professore encerraram o manifesto destinado ao Imperador com o seguinte apelo: "V. M. Imperial comprehende que, assim, maltratada, a classe não tem os elementos indispensáveis para cumprir a alta missão que esta incubida (MANIFESTO DOS PROFESSORES PÚBLICOS PRIMÁRIOS DA CORTE IMPERIAL, 1871, p. 14).

Ainda em relação aos demais funcionários públicos, os professores dirigiram um Manifesto ao corpo legislativo em que solicitavam que seus salários fossem equiparados aos segundos oficiais das secretárias de Estado, pois, segundo os professores, em 1854 as duas funções recebiam os mesmos valores, mas que em 5 de março de 1859 ocorrera a reforma das secretarias de Estado, tendo os funcionários recebido aumentos enquanto os professores continuaram com os mesmos vencimentos de 1854 , e sendo que na década de 1860 a moeda passara por uma forte depreciação e corte por uma carestia dos gêneros alimentícios. Com o aumento dos vencimentos dos funcionários das secretarias em 1859, os professores, que antes se equiparavam em salários com os segundos oficiais, passaram a ser menos remunerados que os contínuos de secretaria. Ao que os professores, no Manifesto afirmavam que: 
Os abaixo assignados fazem justiça aos sentimentos de V. Ex., e estão seguros de que V. Ex. ficará sorprendido, como toda a nação há de ficar, quando souber que um correio, um continuo, de que nenhuma habilitação se exige; que nenhuma responsabilidade tem no desempenho de suas funcções; que tem sua cavalgadura e sua etapa, percebe 1:400\$; e que os professores públicos só percebem 1:200\$, sendo ordenado 800\$!! (MANIFESTO DOS PROFESSORES PÚBLICOS PRIMÁRIOS DA CORTE IMPERIAL, 1871, p. 16).

Concluindo que seu trabalho, em relação ao serviço dos secretários:

[...] os excedem, tanto em trabalho, quanto em responsabilidade. Quanto a categoria, a modéstia não permitte pretender a superioridade; mas a inferioridade, essa a nossa dignidade manda repellir \$!! (MANIFESTO DOS PROFESSORES PÚBLICOS PRIMÁRIOS DA CORTE IMPERIAL, 1871, p. 15).

Os professores reclamavam, igualmente, dos valores das gratificações pagas aos adjuntos. "Será possível?" - perguntavam eles "que possão desempenhar esses funccionários conscienciosamente sua missão com 240\$, 300\$ e 360\$, quando se exigem delles tantas provas de capacidade moral e intellectual?" (MANIFESTO DOS PROFESSORES PÚBLICOS PRIMÁRIOS DA CORTE IMPERIAL, 1871, p. 16).

Diante desse quadro, os professores organizaram, assim, a proposta que encaminhada em 1871 ao parlamento do Império:

Resumindo o que impetrão a V. Ex., os abaixo assignados formulam assim sua petição:

1. Que sejão os professores públicos de instrucção primaria da corte equiparados em vencimentos aos 20 . Officiaes de secretaria.

2. Que os adjuntos de 3a. classe sejão equiparados aos praticantes das mesmas secretarias.

3. Que os adjuntos de 2a. classe tenhão uma gratificação de $600 \$$ annuaes. 4 Que os adjuntos de 1a. classe tenhão uma gratificação de $400 \$ 000$.

E tão geralmente reconhecida, Exm. Sr., a palpitante necessidade de tirar os professores do estado de abatimento em que jazem, é tão justo o pedido que fazem os abaixo assignados em nome da classe, que não é permitido a ninguém duvidar que V. EX. não perdera essa occasião de ligar o seu nome a um melhoramento do maior alcance para os futuros destinos do paiz.

Os abaixo assignados, pois, desde já beijão as mãos de V. Ex., a quem protestão eterno reconhecimento.

Deus guarde a V. Ex. - Rio de Janeiro, 20 de Junho de 1871. - $\quad$ Manoel José Pereira Frazão (relator); Candido Matheus de Faria Pardal; João José Moreira (MANIFESTO DOS PROFESSORES PÚBLICOS PRIMÁRIOS DA CORTE IMPERIAL, 1871, p. 17).

Os professores primários da Corte Imperial não tinham sorte diferente dos professores primários de outras Províncias do Império e, segundo demonstram os 
jornais pedagógicos portugueses do período ${ }^{5}$ ou os estudos de Oliveira ([1873] 2003), não tinham sorte diferente de muitos professores primários de outros países.

\section{Conclusão}

É possível constatar, pelas fontes trabalhadas, que as escolas da Corte funcionavam, em sua maioria, em espaços considerados como não apropriados pelos professores e pelo Estado Imperial. Faltavam prédios públicos e privados em condições para abrigar as escolas, os aluguéis na Corte eram altos, como, ao que parece, os preços de forma geral, produzindo, assim, um grande impacto sobre o salário dos professores, seus vencimentos eram baixos, mesmo em relação a outros funcionários públicos menos qualificados do baixo escalão da burocracia imperial. Os professores, morando nas escolas onde lecionavam, viam o espaço público e privado se integrarem e se confundirem nos limites da profissão. A questão da remuneração dos professores públicos era um ponto fundamental. Aos baixos salários ainda se somava o desconto para o pagamento do aluguel. Da mesma forma que, junto com a desvalorização econômica vinha a desvalorização da capacidade profissional, muitas vezes utilizada como argumento pelos poderes do Estado. Aos problemas encontrados no exercício do ofício, como a falta de condições das escolas, os baixos salários e defesa dos professores, as tentativas de atribuírem os fracassos da instrução pública ao suposto despreparo dos professores, os professores se levantaram e se organizaram de diferentes formas; diante de um trabalho ímprobo e fatigador, os professores afirmavam a importância do magistério público primário. Em diversos espaços na Corte os professores se reuniam e debatiam os problemas e perspectivas do ofício, organizando-se, ocupando espaços na imprensa, fundando jornais pedagógicos. Participavam e discutiam nas Conferências Pedagógicas, reunindo-se em associações científicas, literárias, beneficentes e profissionais, lutando tanto por melhor remuneração como por uma melhor instrução pública.

5 Cf. Nóvoa (2005). 


\section{Referências}

ALMEIDA, M. A. Memórias de Um Sargento de Milícias. Rio de Janeiro: O Globo, [1854] 1998.

ARQUIVO GERAL DA CIDADE DO RIO DE JANEIRO (AGCRJ). Códice 11 - 1 - 4 Ofícios diversos sobre escolas.

ARQUIVO GERAL DA CIDADE DO RIO DE JANEIRO (AGCRJ). Códice 11 -2 -30 - Ofícios diversos sobre escolas.

ARQUIVO GERAL DA CIDADE DO RIO DE JANEIRO (AGCRJ). Códice 11-4-27 Requerimentos (1875).

BIBLIOTECA NACIONAL. A Instrucção Pública. Publicação Hebdomadária. Rio de Janeiro: Typografia. Cinco de março, 1872 - 1888. PRSOR 3795 (1 e 2) microfilmado (BN).

BIBLIOTECA NACIONAL. A Verdadeira Instrucção Pública. Rio de Janeiro, 1872. PRSOR 3707 (1) microfilmado (BN).

BIBLIOTECA NACIONAL. Brasil. Relatório do Ministro dos Negócios do Império - 1845 1880.

BIBLIOTECA NACIONAL. Brasil. Ministério do Império. Ministro Paulino José Soares de Souza, Relatório do Anno de 1868, apresentado a Assembléia Geral Legislativa na $1^{\mathfrak{a}}$ sessão da 14ạ legislatura.

BIBLIOTECA NACIONAL. Manifesto Dos Professores Públicos Primários da Corte. Rio de Janeiro: Typographia de J. Villeneuve e Cia, 1871.

BIBLIOTECA NACIONAL. Brasil. Coleção de leis Provinciais, 1835-1860. Rio de Janeiro. Typographia Nacional, 1882.

DURÃES, S. J. A. Qualificação do Trabalho Docente em minas Gerais na Segunda metade de Oitocentos. In: YAZBECK, D.C.; ROCHA, M.B.M. da (Orgs.). Cultura e História da Educação: Intelectuais, legislação, cultura escolar e imprensa. Juiz de Fora: Editora UFJF, 2009. 
DURÃES, S. J. A. Acerca do Valor de ser professor(a): remuneração do trabalho docente em Minas Gerais (1859-1900). Revista Brasileira de História da Educação, Campinas, v1, n. 14. p.145-176, Mai./Ago. 2007.

FARIA FILHO, L. M; VIDAL, D. G. As lentes da história: estudos de história e historiografia da educação. Campinas: Autores Associados, 2005.

FRAZÃO, Manuel José Pereira. Cartas do professor da Roça. Rio de Janeiro: Typ. Paula Brito, 1864.

GONDRA, J. (Org.). Dos arquivos à escrita da história. A educação entre o Império e a República. Bragança Paulista: Universidade de São Francisco, 2001.

GOUVÊA, Maria Cristina. Mestre: profissão professor (a) - processo de profissionalização docente na província Mineira no período imperial. In: Revista Brasileira de História da Educação, Campinas. n², p.39-57, jul/dez. 2001.

NÓVOA, Antonio. Evidentemente: Histórias da Educação. Porto: ASA Editores. 2005.

OLIVEIRA, A. A. O ensino público. Brasília: Senado Federal, [1873] 2003.

Enviado em Julho/2013

Aprovado em Agosto/2014 